\title{
Real Time Solid Waste Management System using Solar Energy
}

\author{
Mensah Yaw $^{\# 1}$, Eze Monday ${ }^{\# 2}$, Ogunlere Samson ${ }^{\# 3}$ \\ Department of Computer Science,Babcock University, Ilisan-Remo, Ogun, Nigeria \\ ${ }^{1}$ mensahy@babcock.edu.ng \\ 2 ezem@babcock.edu.ng \\ 3 ogunleres@babcock.edu.ng
}

Abstract - Solid waste management is one of the demanding environmental challenges confronted by urban and rural areas of Nigeria. Trash is being thrown in open areas by people without a second thought on the consequences. Such trash gets carried away by wind or rain into the drains and becomes a source of obstruction with time thereby stopping free flow of water. The main problem in waste management is that overflow of garbage occurs in public bins before the next cleaning process is carried out and this has led to huge environmental pollution and epidemics in the society. To avoid all such hazardous scenario and maintain public cleanliness and health, a real time solid waste management system using an autonomous power supply is needed. The main aim of this research is to develop a real time solid waste management system that will be able to monitor the garbage fill level of the waste bin, update an online database and send notification for proper collection at the same time. This process is aided by the ultrasonic sensor which is interfaced with Arduino ATmega328 microcontroller to check the level of garbage filled in the dust bin and send SMS to notify an authorized waste management personnel and also updating an online database. The real time status of the garbage fill level is displayed on a web application which helps the waste management authority to determine the right to carry at any time. In addition, a Solar panel was attached to the waste bin in order to power the waste bin to prevent down time. In this way environmental condition of the country will be improved.

Keyword-Real Time, IoT, Ultrasonic Sensor, ATmega328 microcontroller, GSM module, Solar panel

\section{INTRODUCTION}

Waste can come in different forms which are gas, liquid or solid and each have different ways of management. Waste management typically deals with any kinds of wastes whether created from industrial, biological, household, and special in which it is dangerous to human health [1]. Solid waste management is a pressing environmental challenge faced by urban and rural areas of Nigeria. Nigeria, with a population of 195,448,220 [2] as of May 31, 2018, is one of the largest producers of solid waste in Africa. She generates more than 32 million tons of solid waste annually, out of which only $20-30 \%$ is collected by local authorized solid waste management companies within the country [3]. Reckless disposal of solid waste has led to blockage of drainage networks and choking of water bodies because trash is being thrown in open areas by people without a second thought of the consequences. Such trash gets carried away by wind or rain into the drains and becomes a source of obstruction with time thereby stopping free flow of water. As Nigerian cities continue to experience rapid urbanization, the resulting solid wastes generated by households have grown beyond what the capacity of local authorities could effectively manage [4]. The wastes generated by households, local industries, artisans and traders which litter the immediate surroundings lead to environmental catastrophe. The aim of this study is to develop a real-time system that is autonomous in terms of power supply and can effectively manage collection and disposal of waste within the country.

\section{RELATED WORK}

There are some pervious researches on the use of real time systems to solve the problems of solid waste management. [5], carried out a study on Smart Waste Management using Internet of things (IOT). The main aim of the study was to use Waste Collection Bins Based on Sensor to classify the status of waste bins when full or empty in order to prioritize the schedule for the collection waste accordingly to save cost. It is a real-time waste management system which uses an intelligent dustbin to check the garbage fill level of dustbins whether the dustbins are full or not. Using the device, the data of all the smart dustbins is easily accessed from any point and anytime by the waste personal. The status of each dustbin is updated in real time so that waste management authority can send the garbage collection vehicle to the right dustbin when the dustbin is full. However, there are some drawbacks that needed to be overcome such as power supply because in a country like Nigeria where there is no stable power supply this system will not meet its goal. 
Harika, [6] carried out a study on IoT Based Smart Garbage Monitoring and Alert System Using Arduino UNO. Arduino UNO is the main Module in the project. The Ultrasonic sensor is used to interface with Arduino UNO to check the filling of the garbage level in the dustbin. GSM/GPRS Module is used to establish communication between a user computer and a GSM-GPRS system and using this module one gets the SMS notification from the trashcan. GPS Module is a navigation device that indicates the location where garbage is filled and by using Wi-Fi Module, one gets unique IP-address for SMS and also Municipal Officer can see the garbage bin status in "All things talk" web site. Three LED bulbs indicate the garbage level in the trashcan. Yellow LED indicates the empty in the dustbin, Green LED represents the half of the dustbin is filled, Red LED indicate the trashcan is filled. Then immediately message is transferred to Municipal Wed Server Office. The limitation of the system is that the system does not have a customized database. It depends on a third-party database management system and also it relies on power supply.

[7], carried out a study on waste monitoring and management for Smart cities. MQTT (Message Queue Telemetry Transport) protocol on a cloud-based app was used to receive data from a node by the system. MQTT is lightweight and needs limited network bandwidth, making it optimal for such short messages. A NoSQL database waste used to allow flexibility in order to test which data might be useful to send and store without major changes to the database. The system was able to monitor dustbins and waste bins using a cloud database. The system uses Message Queue Telemetry Transport protocol (MQTT) which is not commonly supported by Nigeria network.

\section{P PROPOSED MODEL}

The proposed model is a Hybrid architecture which comprises of hardware, backend, mobile phone and frontend as shown in Figure 1.

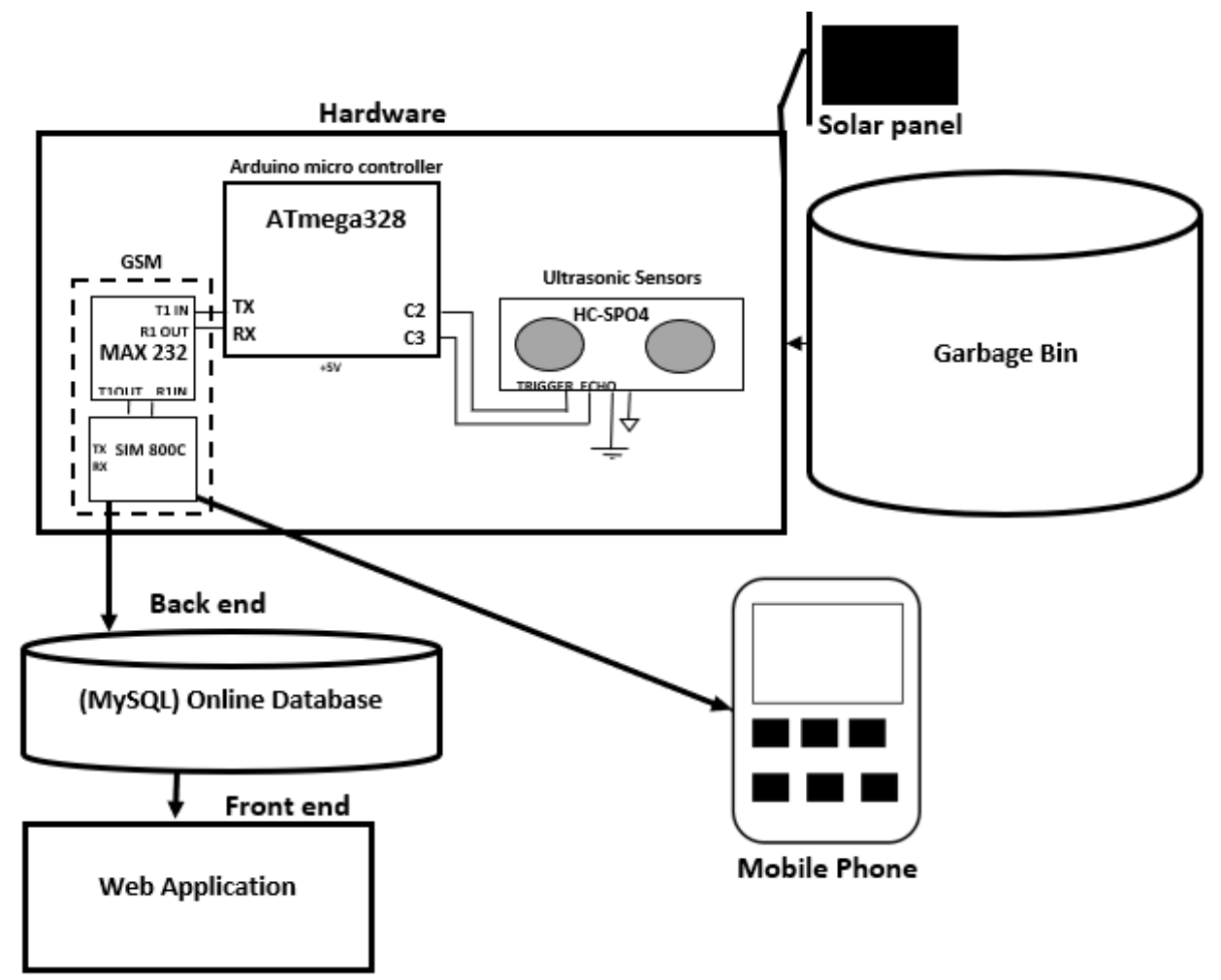

Fig. 1. The Real Time Solid Waste Management Model

\section{1) The hardware}

The hardware is made up of ATmega328 microcontroller, HC-SP04 ultrasonic sensor, SIM800C GSM module, and a Solar panel. ATmega328 is made up of 14 digital input/output pins (out of which 6 used for Pulse Width Modulation (PWM) outputs), 6 analog inputs, on-board resonator, reset button, and holes for mounting pin headers. It consists of 16 bit and one 32bit timer/counter. Timer 1 is used for connecting the ultrasonic sensor HC-SR04 with the microcontroller. The microcontroller is equipped with Tx and Rx pin for serial communication. These pins are connected to the GSM module through the inbuilt MAX 232IC present at the module. The GSM module is connected to the Tx and Rx pin using the inbuilt MAX 232IC pin. MAX 232IC serves as a converter which convert the logic from TTL to RS232, while the GSM module and the ATmega328 microcontroller operates at RS232 and TTL logic respectively as shown in Figure 1. 


\section{2) The Backend}

The backend provides an interface where computing such as memory and processing are made available through the help of online database management companies. The online database management system has a relational database used to store the garbage level record for further use.

\section{3) The Frontend}

The frontend contains the web application that displays the real-time view of the garbage level for the waste bin container. The frontend is the interface where the solid waste management personnel or garbage analyzer will login to view the garbage level of the bin. The IP of the bin will be used on the frontend application, so as to identify the bin and its location at any point. This helps the garbage analyzer to keep track of dustbin filled in exact location and that will help in taking accurate decision in other to avoid the overflow of dustbins and use the resources more efficiently.

\section{4) The Mobile Phone}

The phone provides an interface where the solid waste management personnel or garbage analyser receives an alert or notification from the garbage bin prompting the filled level notification for the garbage collection team to collect the garbage from the bins.

\section{A. Process Mathematical Expression}

Figure 2 shows the general process of how the garbage level is determined by the real time solid waste management system.

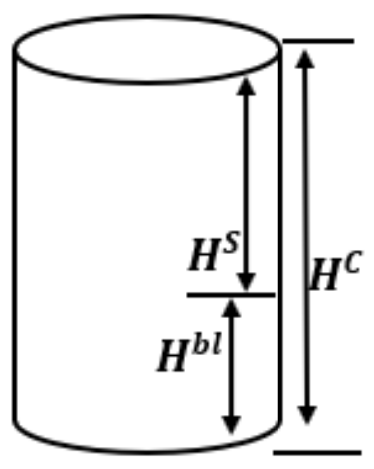

Fig. 2. Garbage level determinant by the real time solid waste management system

The following equations are used to determine the levels and operation of the garbage bin.

$$
\begin{aligned}
H^{S} & =\left(\begin{array}{c}
H 1 \\
H 2 \\
H 3 \\
H 4 \\
\cdot \\
\cdot \\
\cdot \\
H n
\end{array}\right) H^{C}=\left(\begin{array}{c}
H 1 \\
H 2 \\
H 3 \\
H 4 \\
\cdot \\
\cdot \\
\cdot \\
H n
\end{array}\right) H^{b l}=\left(\begin{array}{c}
H 1 \\
H 2 \\
H 3 \\
H 4 \\
\cdot \\
\cdot \\
\cdot \\
H n
\end{array}\right) \\
H^{S} & =H^{C}-H^{b l}
\end{aligned}
$$

where:

' $H^{C}$ ' is a column vector representing the height of the waste bin

Hi such that $i=1,2,3,4,-,-,-, n$.

' $\boldsymbol{H}$ ' ' is a column vector representing the height of the space in the waste bin

Hi such that $i=1,2,3,4,-,-,-$, .

' $\boldsymbol{H}^{\boldsymbol{b l}}$ ' is a column vector representing the height of the bin level in the waste bin

Hi such that $\mathrm{i}=1,2,3,4,-,-,-$, .

' $\boldsymbol{H}$ ' ' height of the space left in the waste bin isdetermine by the ultrasonic sensors which sends out an ultrasonic high-level pulse for at least $10 \mu \mathrm{s}$ and detecting the returning pulse which serve as the interval of sending signal and receiving echo with respect to time in order to determine the distance whereby using it to update database.

$$
\boldsymbol{H}^{b l}=\boldsymbol{H}^{c}-\boldsymbol{H}^{s}-----(2)
$$

To determine ' $\boldsymbol{H}$ ' , which is the level of garbage in the waste bin, the height of the space in the bin is subtracted from the original height of the bin which is been preloaded in the database using PHP as shown in equation 2. 


$$
\% H^{b l}=\frac{H^{b l} X 100}{H^{C}}
$$

The percentage bin level $\mathbf{6} \% \boldsymbol{H}^{\boldsymbol{b l}}$, is then calculated using equation 3. Equation 2 and 3 is implemented on the server side of the web platform using PHP.

\section{B. Process Flowchart}

The process flowchart for the waste bin operation is shown in Figure 3 below.

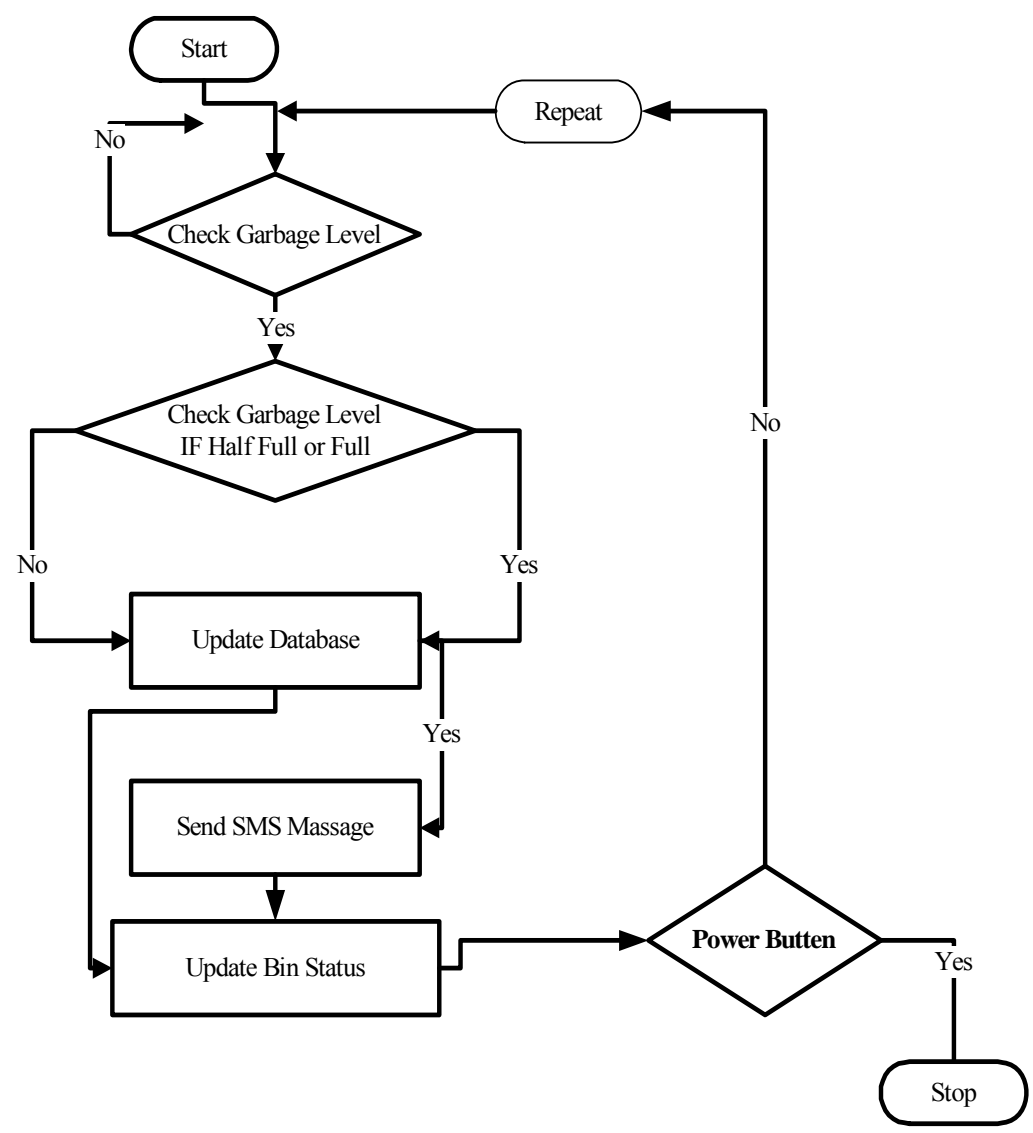

Fig. 3. Garbage level determinant by the real time solid waste management system

As shown in the flow diagram, the system loops the garbage check continuously, unless there is an interruption as depicted in the decision symbol (power Button). The system also keeps updating the database and sends SMS accordingly.

\section{Use Case Diagram}

The use case diagram of the system is shown in Figure 4. 


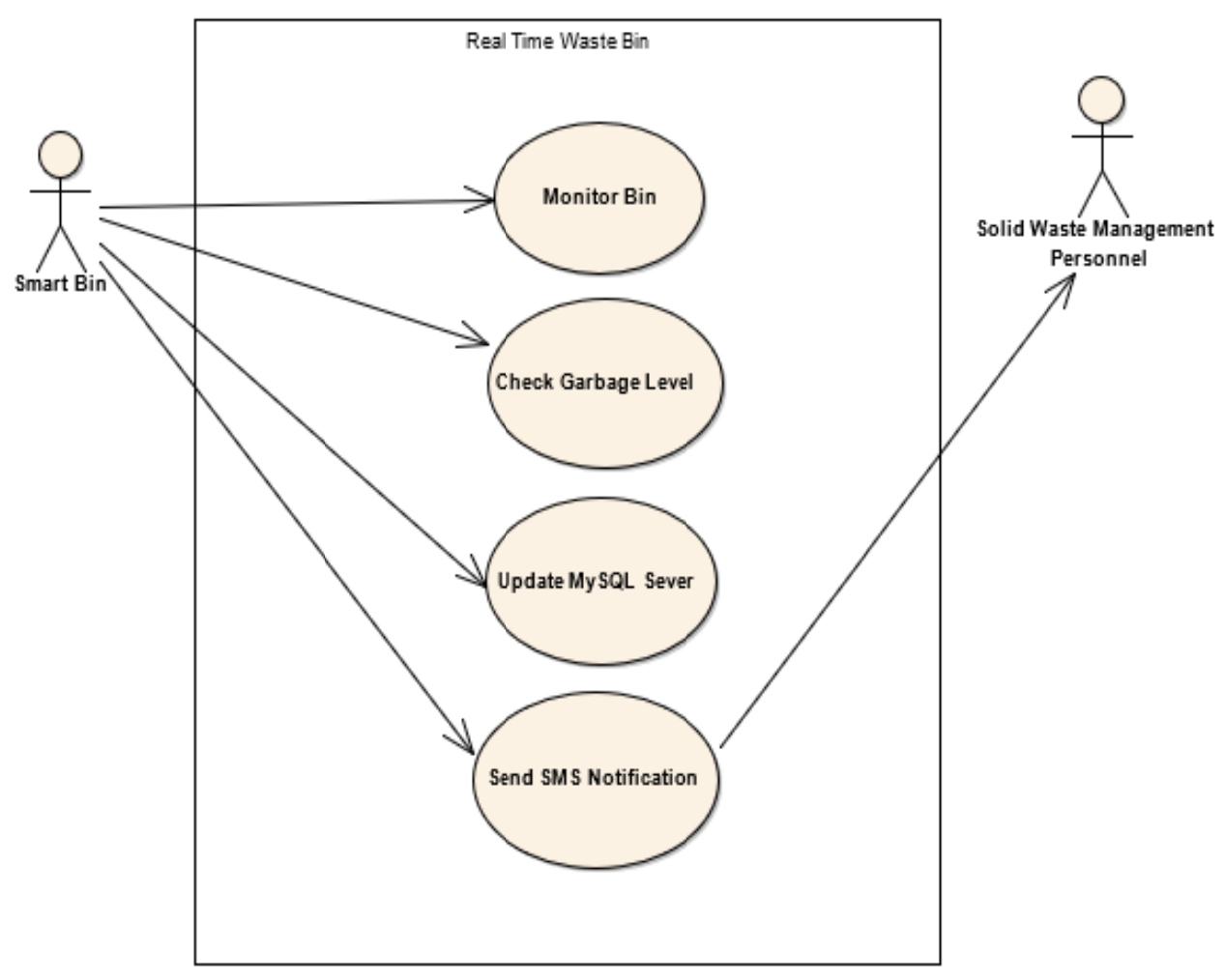

Fig. 4. Use Case Diagram for Real Time Waste Bin Operation

\section{IV.SYSTEM IMPLEMENTATION}

Figures 5 and 6 shows Hardware implementations of the system. The hardware device is placed at the top of the bin in order to measure the garbage level in the waste bin. The Dustbin has three levels which are listed as follows EMPTY level, HALF FULL level and FULL level. EMPTY level is equal to 0\%, HALF FULL level is between $50 \%$ and $53 \%$ FULL level is between $85 \%$-to $-100 \%$. The monitoring and measurement stages were divided into three. At first stage, the combination of ultrasonic sensor, GSM module and Arduino microcontroller generates a unique IP address and then INSERT into a table on the online database using GPRS. At the second stage the system measures the garbage level height in the waste bin and update the garbage level table on the database using the unique IP address generated. At the third stage the system checks if the garbage level in the waste bin is HALF FULL or FULL and then sends SMS to a mobile phone using GSM (Global System for Mobile) module. Figure 7 shows the dashboard developed to display the real time view of the system. It has two views which are super admin and user admin view, each are accessed according to their priorities.

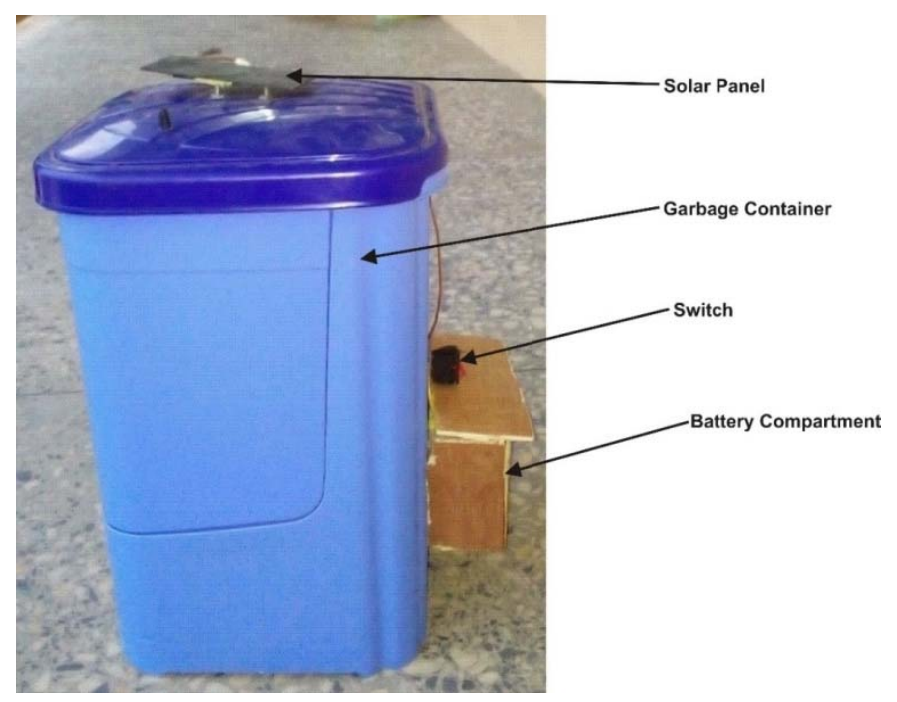

Fig. 5. Real Time Solid Waste Bin 


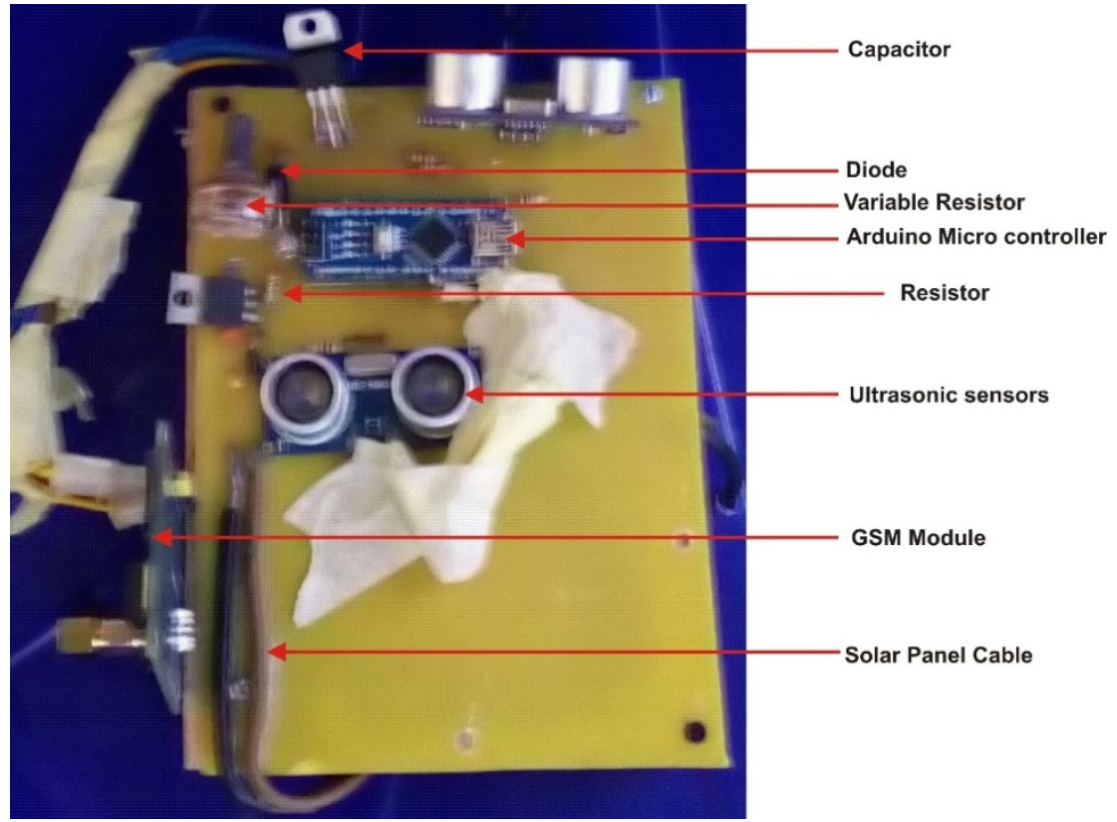

Fig. 6. Hardware Device for Garbage Monitoring

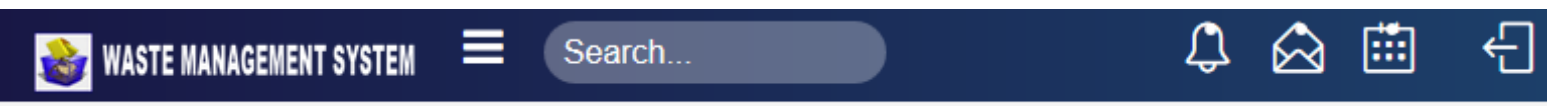

\section{Dashboard}

* / Dashboard

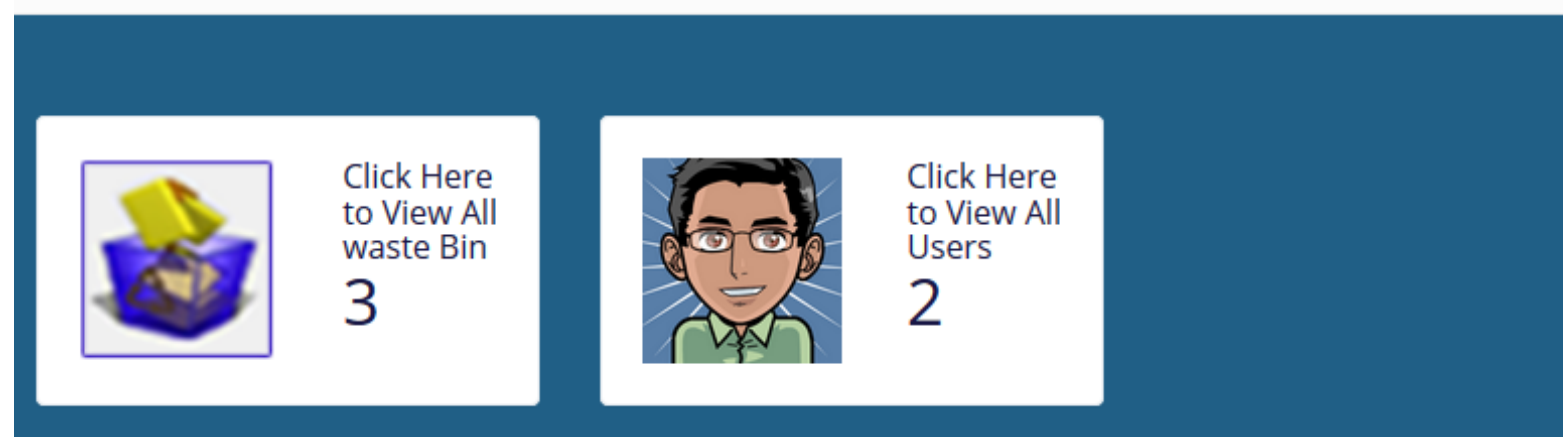

Fig. 7. Waste Management System Dashboard

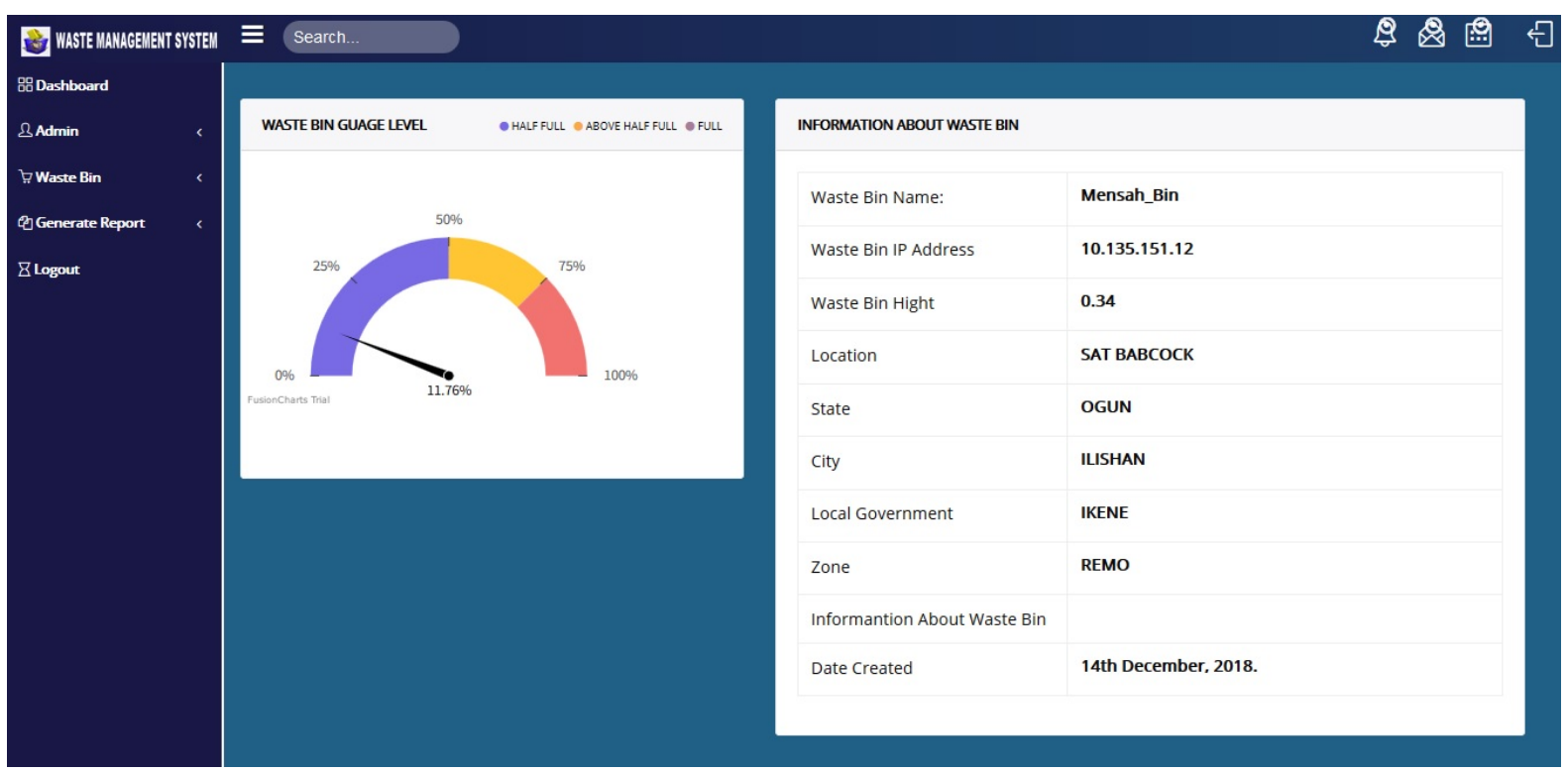


Fig. 8. Waste Bin Level Page Waste Management System

\section{System Testing and Experimental Results}

Five (5) tests were carried out on the system which completed 1 cycle of loading the garbage bin, in two different locations which are Babcock University Ilisan Remo Ogun State and Seventh-Day Adventist Church Compound Oke Bola Ibadan Oyo State. The empirical outcome of the test is shown in Tables 1 and 2 representing the filling level of the ultrasonic sensor placed at the top of the bin. The garbage level with respect to height was tested under different conditions as shown in Tables 1 and 2. When the bin was empty the height was Zero percent " $0 \%$ ". Gradually the bin was loaded with garbage; at a certain point when the bin was half full an SMS was sent to the phone notifying filling level, then as loading the bin with garbage continues, it got to another point when the bin was almost filled up another SMS was sent notifying the garbage level is full. The height of the bin is $34 \mathrm{~cm}$ and equation 3 was used to calculate the percentage level as shown in Tables 1and 2.

TABLE I. Experimental data from several tests run of the prototype

\begin{tabular}{|c|c|c|c|c|c|}
\hline Test & Bin Height (cm) & Bin Space (cm) & Bin Level (cm) & \% Level & Status \\
\hline 1 & 34 & 34 & 0 & 0 & EMPTY \\
\hline 2 & 34 & 17 & 17 & 50 & HALF FULL \\
\hline 3 & 34 & 16 & 18 & 53 & HALF FULL \\
\hline 4 & 34 & 5 & 29 & 85 & FULL \\
\hline 5 & 34 & 0.5 & 33.5 & 99 & FULL \\
\hline
\end{tabular}

TABLE III. Experimental data from several tests run of the prototype

\begin{tabular}{|c|c|c|c|}
\hline Test & Bin Level (cm) & \% Level & Status \\
\hline 1 & 0 & 0 & EMPTY \\
\hline 2 & 17 & 50 & HALF FULL \\
\hline 3 & 18 & 53 & HALF FULL \\
\hline 4 & 29 & 85 & FULL \\
\hline 5 & 33.5 & 99 & FULL \\
\hline
\end{tabular}

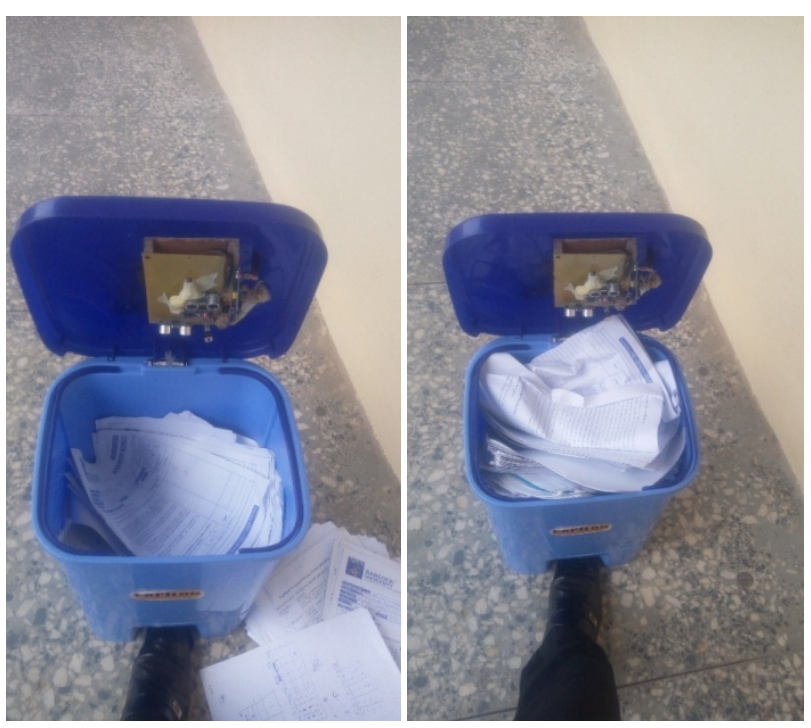

Fig. 9. Smart Waste Bin Process Testing

The SMS samples are shown in Figure 10. 


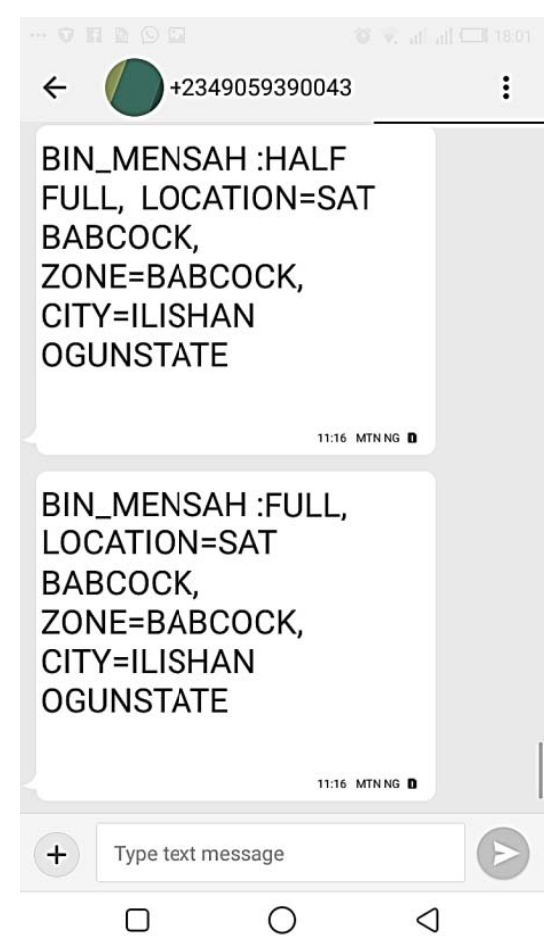

Fig. 10. Sent Text Message to Mobile

\section{CONCLUSION}

It is possible to achieve a more efficient system than the existing ones by using sensors to monitor the fullness of bins. Our idea of "Real time solid waste management system", mainly concentrates on monitoring and collection of waste management. By implementing this research, garbage collectors or personnel are notified early enough thereby eliminating over flowing of waste from the garbage bin and also improving the environmental condition in the urban and rural areas in Nigeria.

\section{ACKNOWLEDGMENT}

Considering the pressing environmental challenges faced by urban and rural areas in Nigeria, due to reckless disposal of solid waste that lead to blockage of drainage networks and choking of water bodies. There is necessity for a real time solid waste management system that will effectively and efficiently manage the monitoring and collection of waste. This will help to improve the environmental condition within the country. The fact that the system is using an autonomous power supply, it can be implemented or deployed at any part of the country. We therefore recommend that every local authority waste management company or house hold should employ this system for effective management. Further work shall focus on effectiveness and efficiency of the garbage collection process by using fussy logic to determine the movement and position of all garbage truck at any time and then notifying the nearest truck for garbage collection.

\section{REFERENCES}

[1] Editorial Board/Aims \& Scope. (2014). Waste Management. Elsevier, 1-5.

[2] Worldometers. (2018, may 31). Nigeria Population (LIVE): worldometers.info. Retrieved from www.worldometers.info: $\mathrm{http}: / /$ www.worldometers.info/world-population/nigeria-population/.

[3] Bakare, W. (2016, January 19). Solid Waste Management in Nigeria. Retrieved from BioEnergy Consult: https://www.bioenergyconsult.com/solid-waste-nigeria/.

[4] Andrew, O. (2015). Determinants of Solid Waste Generation and Disposal Systems Among Neighbourhoods in Benin City. International Journal of Social Sciences and Humanities Reviews, $1-10$.

[5] Nagajothi, S., Durga, J., Jayasurya, K., Vishnuvarshini, M., \&Nadhiya, M. (2018, March). Smart Waste Management using IOT. International Journal of Advanced Research in Computer and Communication Engineering (IJARCCE), 7(3), 160 - 163.

[6] Harika, K., Muneerunnisa, R. V., Venkateswara, R. P., \&SreeLakshmi, L. (2018, February). IOT Based Smart Garbage Monitoring and Alert System Using Arduino UNO. International Journal of Innovative Research in Computer and Communication Engineering, 6(2), 1573 - 1581. Retrieved from www.ijircce.com.

[7] Andre, L. C., Ali, G., \& Jakob, S. (2017). Smart cities: A case study in waste monitoring and management. 50th Hawaii International Conference on System Sciences (pp. 1392 - 1401). Hawaii :Scholer space - University of Hawai'i at Manoa .FLEXChip Signal Processor (MC68175/D), Motorola, 1996.

[8] Anthopoulo, L. G. (2015). Understanding the Smart City Domain: A Literature Review. Public administration and information technology $2,50-62$.

[9] Anton, H. A. (2003, july 31). The Worldwide History of Telecommunications. John Wiley \& Sons, $529 .$.

[10] Florence, N. (1954). Selected Writings of Florence Nightingale. In L. R. Seymer, Modern History (p. 38287). New York: The Macmillan Co.

[11] Gandy, M. (1994). Recycling and the Politics of Urban Waste. New York: Earthscan. 
[12] Lawrance, M., \& Woods, E. (2014). Advanced collection, processing, energy recovery, and disposal technologies for the municipal solid waste value chain. Global market analysis and forecasts.

[13] Mahajan, S., Kokane, A., Shewale, A., Shinde, M., \&Ingale, S. (2017, Apr.). Smart Waste Management System using IoT. International Journal of Advanced Engineering Research and Science (IJAERS), 4(4). Retrieved from https://dx.doi.org/10.22161/ijaers.4.4.12

[14] PHP Manual. (2009). Introduction: What can PHP do. PHP ini. PHP Group. Retrieved 11 29, 2018, from www.php.net.

[15] MySQL. (2018, August 26). Doc: MySQL. (Oracle Corporation) Retrieved january 2019, from MySQL: https://dev.mysql.com/doc/refman/8.0/en/history.html

[16] Mattern, F., \&Floerkemeier, C. (2016). From the Internet of Computers to the Internet of Things. ETH Zurich.

[17] Meyer, E. A. (2006). Cascading Style Sheets: The Definitive Guide (3rd ed.). O'Reilly Media, Inc.

\section{AUTHORS PROFILE}
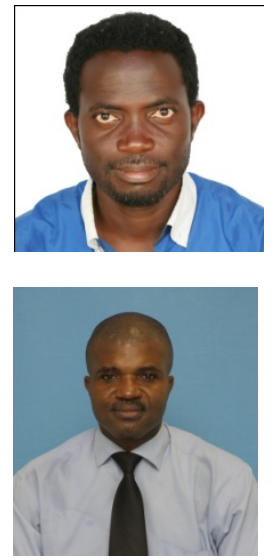

Mensah Yaw Agyeiis an MScComputer Science Student from Babcock University, Ilisan-Remo, Ogun State, Nigeria. He has several years of experience in computing. He is currently a technologist in the department of Computer Science, Babcock University, Nigeria. He is an Associate member of the Nigeria Computer Society of Nigeria. His areas of interest are Microcontroller Application and Information Technology. He has published works in several journals of international repute.

Eze Mondayis a Senior Lecturer and Postgraduate Coordinator in the Department of Computer Science, Babcock University, Ogun State Nigeria. He has a Bachelors' Degree (BSc) in Computer Science, MBA in Management, MSc in Computer Science, and a PhD in Computer Science. He is a full member of the Nigerian Computer Society (NCS) and the International Institute of Informatics and Systemic (IIIS), Florida USA. His research interest includes Computational Algorithms, Data Mining, Heterogeneous Network Modeling, and Robotics.

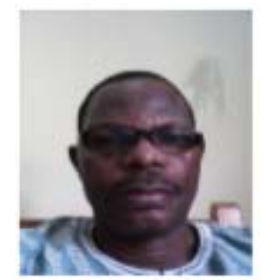

Engr. Ogunlere O. Samson $(\mathrm{PhD})$ is a Senior Lecturer at Babcock University, Computer Science Department in Computer Hardware/ Software related courses. He is a registered member of Nigeria Society of Engineers (MNSE) and COREN with many years working experiences in computer industries. He is also a member of Computer Science Department Research group in Babcock University, Ogun State, Nigeria. 